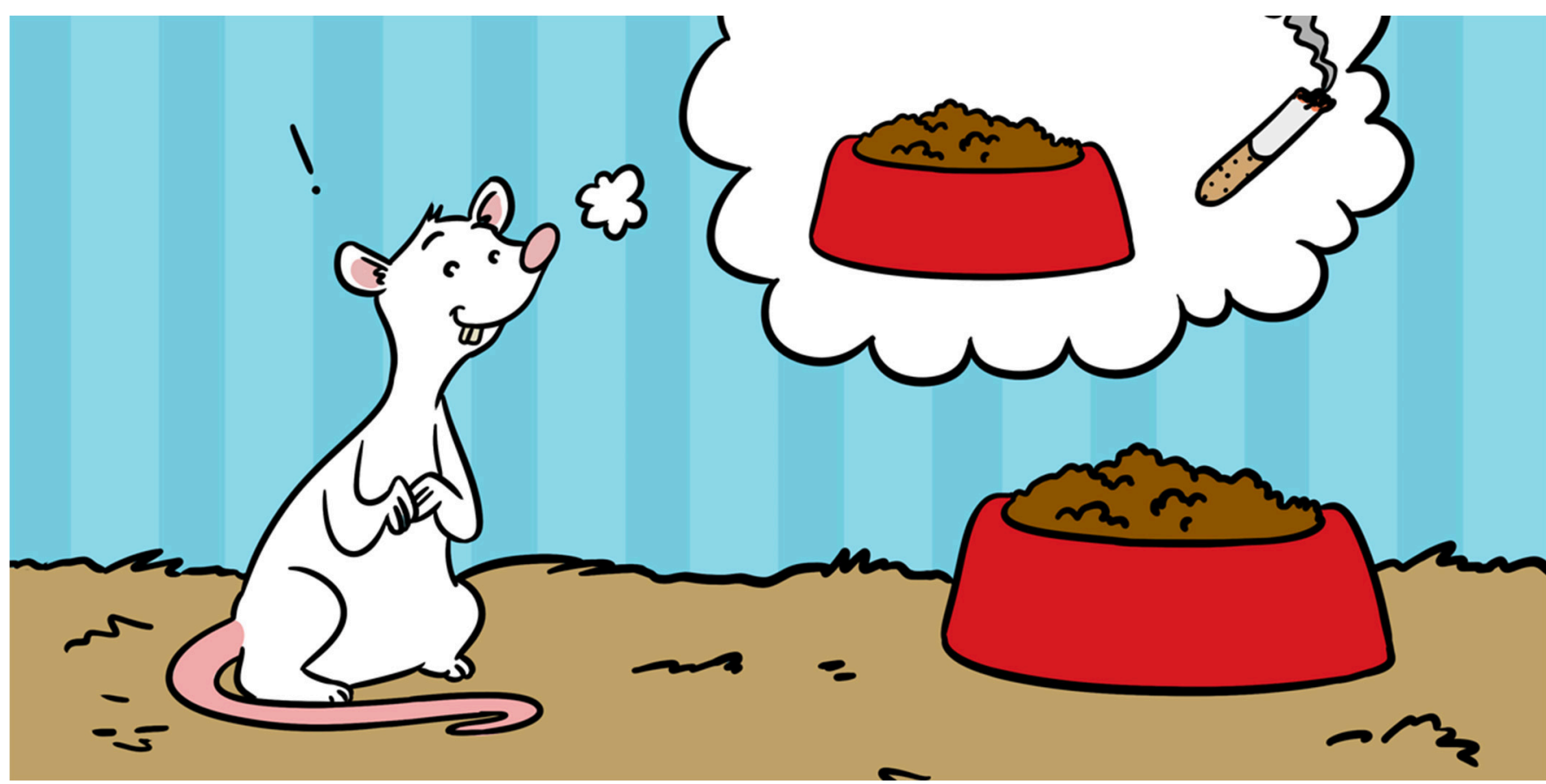

\title{
FROM PAVLOV'S DOG TO RATS USING DRUGS
}

\section{Shaun Yon-Seng Khoo*t}

Center for Studies in Behavioral Neurobiology/Groupe de Recherche en Neurobiologie Comportementale, Department of Psychology, Concordia University, Montreal, QC, Canada

YOUNG REVIEWERS:

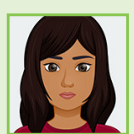

CHAIMA

AGE: 16
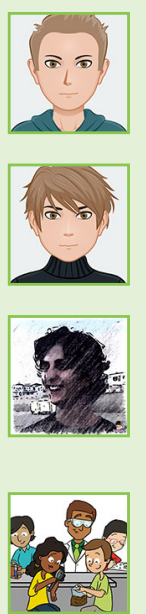

FERGUS

AGE: 14

JACK

AGE: 14

JULIAN

AGE: 15

SCHOOL

WITHOUT

WALLS

AGE: 13
Pavlov's dogs became famous in 1927 for learning that the sound of a bell meant that food was coming. Today, scientists are still interested in understanding how sights, smells, sounds, and places can come to influence our behavior. These things are called cues and contexts. In drug addiction, people experience cues and contexts and drugs around the same time and form mental links or associations between the cues/contexts and the drugs. These mental links can motivate people to seek out drugs even if they are trying to quit. By studying the brain as these mental links are being formed or broken, researchers are learning about one of the things that keeps people from breaking their addictions, and they are improving the therapies available to help people who are addicted to drugs.

\section{INTRODUCTION}

Drug addiction is a mental disorder that hurts people with drug addiction, their friends, family, and wider communities. Addiction involves drug use that a person finds very difficult to control, even as 


\section{ADDICTION}

A mental disorder in which a person cannot control his/her use of drugs or alcohol, even though it causes harm to that person and to others.

\section{CUE}

A stimulus like a sight sound, or smell that does not normally have any meaning on its own. It takes on meaning once it becomes mentally linked with something motivating.

\section{CLASSICAL}

\section{CONDITIONING}

The process of how a previously neutral stimulus (e.g., a sight, sound, or smell) becomes associated with something highly motivating (e.g., food) when the two things are repeatedly experienced together. it creates problems for the person at school, work, and home. Over time, people with addiction might need to take more and more drugs and they can come to rely on drugs so much that trying to quit makes them really sick. Even after people with drug addiction quit, it is very common for them to crave the drugs that they used to take and to eventually relapse and use those drugs again.

One of the reasons drug addiction is so harmful is that young people are most at risk of addiction. Another reason is that, even with the best available treatments, the majority of people with drug addiction will spend years recovering. Instead of living their lives to the fullest, they are often going through cycles in which they use drugs for a while and then quit, over and over again. Scientists know that drug use can be triggered by cues in the environment that remind people of drugs, like certain places, objects, sounds, or smells. This means that it is important for scientists to study these cues. We hope that by better understanding how these mental processes work, better treatments can be developed to help people with drug and alcohol addiction.

\section{HOW CUES AND CONTEXTS CONTROL YOU}

Ivan Pavlov was a physiologist studying the digestive system in dogs, when he noticed that the dogs would begin to drool (or "salivate") when ordinary things happened around the time when food was coming. Pavlov found that he could train the dogs to drool following a particular cue, like the sound of a bell, by presenting the cue before giving the dogs their food [1]. Over time, the dogs would begin to drool when they heard the cue rather than when they received their food.

This process is not limited to dogs. For example, if you go to an ice cream shop a lot and it smells like strawberries, eventually you might come to form a mental link between the ice cream and the smell of strawberries. The smell of strawberries becomes a cue that could cause you to start salivating at the thought of ice cream. This process of forming mental links between environmental cues and something that is highly motivating, such as a food you like, is called classical conditioning.

Scientist have found that classical conditioning also happens in drug addiction. It happens in the same way in drug addiction as it did for Pavlov's dogs or as it might for ice cream. This is because the process of classical conditioning happens in mostly the same way in different species and with different cues or stimuli (Figure 1). When people consume drugs, including alcohol, they often do it in a particular way. They might buy a certain brand of cigarettes or drink alcohol at a certain time of the day. Along the way, they form links between the cues in the environment that they see, hear, and smell and the drug 
Figure 1

Classical conditioning works across many different species.

Pavlov's dogs learned to associate a bell with food, and after a while the sound of the bell caused the dogs to salivate (or drool). In the laboratory, addiction scientists present rats and mice with cues, such as a light, that the animals come to associate with alcohol. After a while, the cues alone can cause the animals to approach a cup looking for alcohol. In humans, the same basic processes occur. For example, product branding may become an alcohol cue and cause someone to crave alcohol and go looking for it. Stock images CCO via pixabay.com and CC BY-SA Wikimedia Commons (Angelo, Abujoy).

\section{CONTEXT}

A combination of cues that is present in the background, usually in a physical place. For example, a classroom would be a different context than a hospital.

\section{ASSOCIATION}

The mental links between a particular cue or context and something highly motivating. In addiction, cues and contexts become associated with drugs and alcohol.

\section{Conditioning Works Across Species}
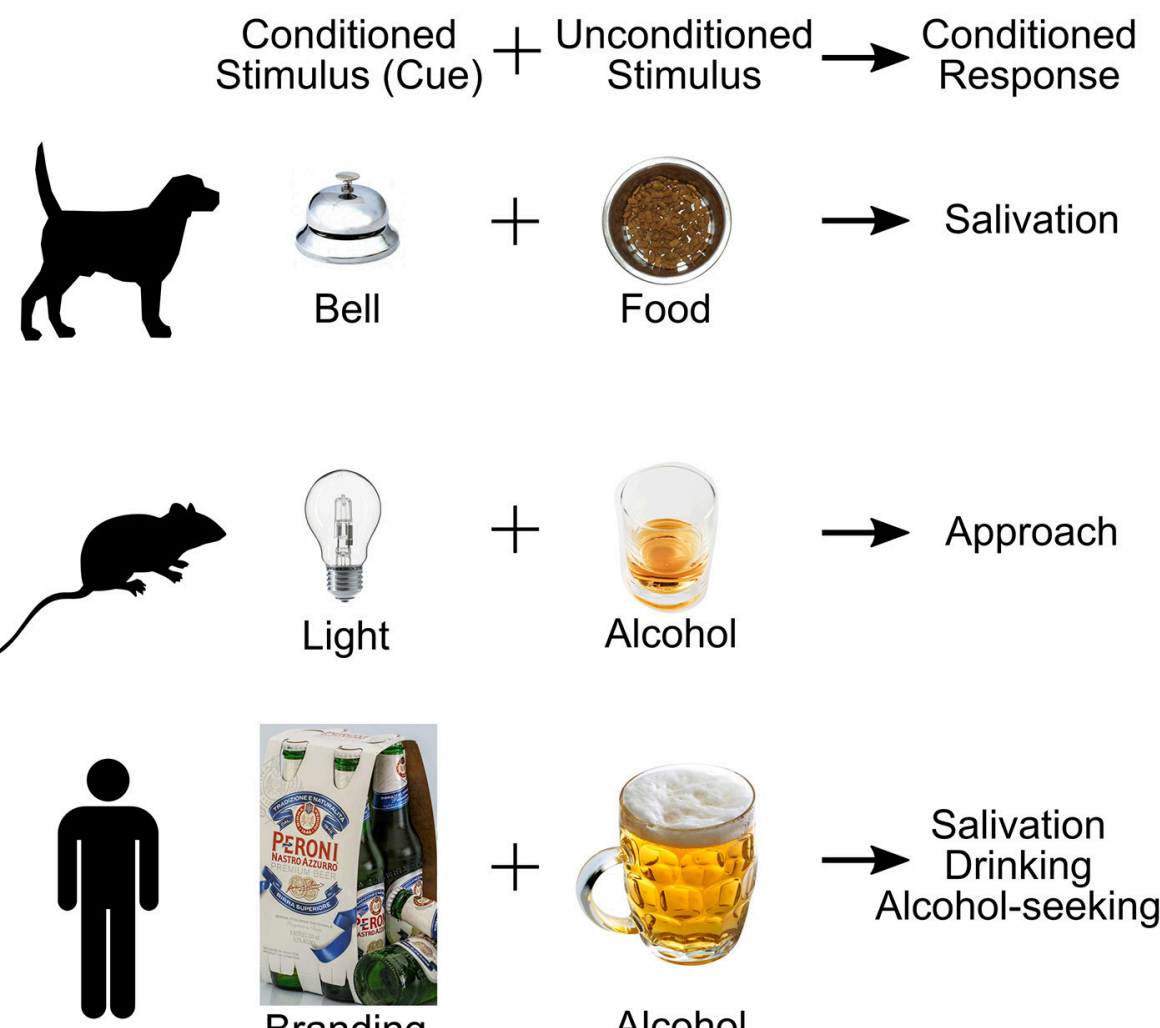

Branding

Alcohol

that they are taking. People who have used drugs for longer or have a more severe addiction tend to react more strongly to the cues and have a harder time giving up the drug they are addicted to [2].

Contexts can also act as cues. A context is made up of multiple features that are always in a specific environment, such as decorations, smells, or sounds. If someone goes to the pub to drink alcohol, then they will come to associate pubs with alcohol. A pub might have a distinct look, smell, and feel. It will have features that are very different from an ice cream shop or a school. These features of the pub are the context, and they can become associated with drinking alcohol and later trigger relapse. For example, if someone is a recovering alcoholic and goes to the pub with their friends, they would be more likely to relapse than if they went home.

\section{DRUG ADDICTION IN THE LABORATORY}

In the laboratory, scientists want to study how the associations between drugs and cues or contexts work. But scientists cannot just test drugs on teenagers-only doctors and pharmacists should be 
Figure 2

The phases of addiction. In the first phase of this example, a rat is placed in a particular context. During the acquisition phase, the rat is shown a light before it receives alcohol. The graph shows time and the number of responses that the rat makes throughout this phase. Over time, the rat will increase the number of responses it makes as it learns that the cue means it will receive alcohol. In the next phase, extinction, the rat is placed in a different context and shown the light but not given alcohol. This mimics therapy and, as shown in the graph, over time the rat will stop responding to the cue light. During reinstatement, the rat is returned to the first context and shown the cue. As shown in the graph, the rat will make a large number of responses at first even though there is no alcohol. Over time, it will stop making responses as it learns that alcohol is not being delivered.

\section{Phases of Addiction: Context Reinstatement}

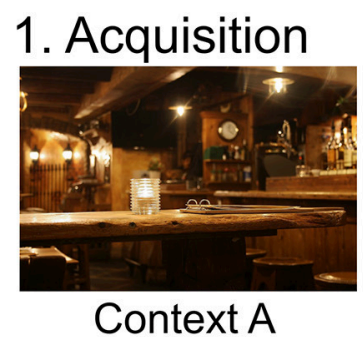

Context A
Cue

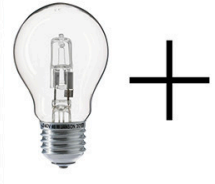

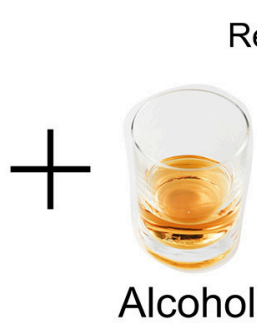

Responses

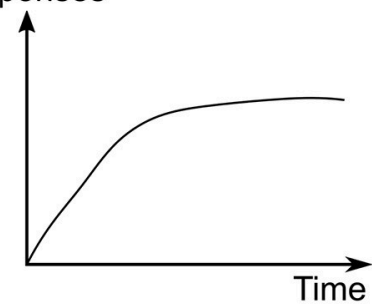

2. Extinction

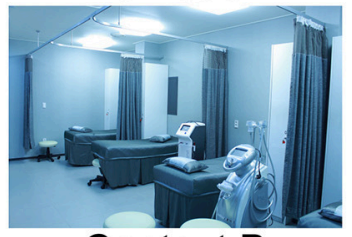

Context B

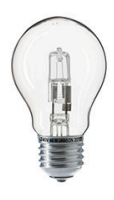

Cue

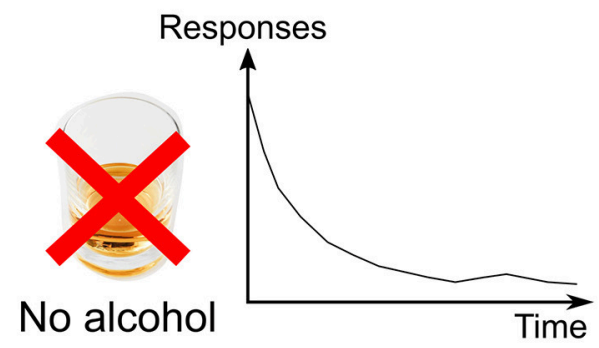

3. Reinstatement

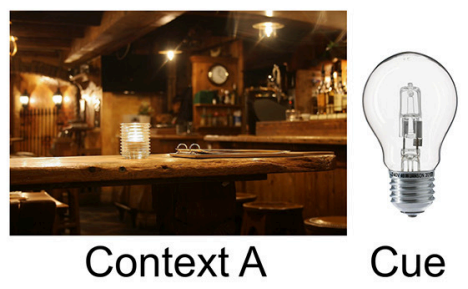

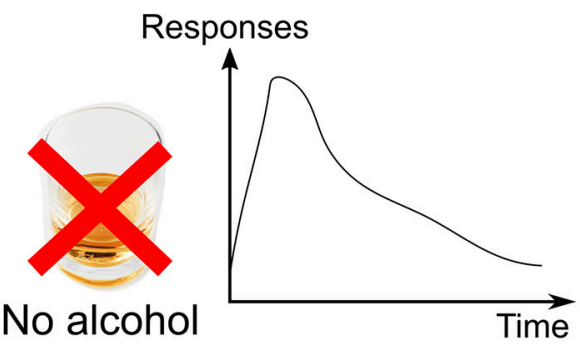

Figure 2 handing out medicine and it is definitely both illegal and unethical for scientists to test addictive drugs on young people! Instead, scientists use animals like rats and mice. This is because rats and mice can also be used to learn about how cues and contexts relate to an addictive drug, because cues and contexts work for them too. These animals will also voluntarily take many kinds of drugs, including alcohol, nicotine (the addictive part of tobacco), cocaine, and heroin.

There are three stages of addiction that scientists are interested in studying. These stages are called acquisition, extinction, and reinstatement. Acquisition relates to the way an animal comes to associate certain cues or contexts with a drug. Extinction mimics the way addiction is often treated, by trying to take the drug away. Finally, reinstatement is like relapse, where the animal is triggered to look for the drug again. In the example shown in Figure 2, scientists are studying how rats come to associate both a particular context and a particular cue with alcohol [3]. 
Acquisition describes the phase when animals have access to the drug. In the example in Figure 2, rats are placed in containers called conditioning chambers, which have been made unique using a certain kind of background, smells, and flooring. These make the context look, smell, and feel different, a bit like how a pub might have its own look, smell, and feel. Then, the rats are presented many times with a cue light that comes on for a few seconds before they get alcohol. At first, they do not notice the cue light. But after the cue light followed by the alcohol happens more and more, the rats will begin to respond to the cue light by approaching the cup where they drink alcohol. After a while, they will have formed a strong association between the cue light and alcohol. Scientists can then study what has changed in the brains of these rats to cause them to respond to the cue and context.

The next phase is called extinction, and it models what happens when someone tries to quit drugs, maybe by getting treatment. In this phase, the rats are placed in a conditioning chamber that looks, smells, and feels different from the first context, where they got the alcohol. This is because alcoholics do not go to see a therapist in the pub. If alcoholics see a therapist or counselor, that would happen in a clinic. In this new context, the rats are shown the cue light but no alcohol is delivered. The idea is to break the connection between the cues and the alcohol. The rats will initially respond a lot, because they will have learned that the cue light means alcohol is coming. Over time though, they will learn that the cue light no longer means alcohol is coming and they will stop looking for the alcohol. Scientists have learned that extinction stops the responses to a cue, but it is difficult to fully erase the entire memory of the cue being associated with the drug [4].

The final phase is called reinstatement and is like relapse. In the example in Figure 2, the rats are put back into the first context. This is a bit like someone who has gone through therapy going back out into the world and seeing all the places where they used to use drugs or alcohol. When the cue light is presented in this context, the rats will respond to it again. Even though there is no alcohol, the rat still looks for it. They will look for the alcohol a lot at the beginning of the session, but this behavior will decrease quickly because it is not reinforced. This might be what happens when humans relapse and is probably like a strong burst of craving for alcohol. Reinstatement is a critical time that many scientists focus on. It is often the most important test of whether an experimental treatment worked, because relapse is such a big problem for humans who suffer from addiction.

\section{HOW DO THESE ANIMAL STUDIES HELP US UNDERSTAND ADDICTION?}

Scientists studying the way that cues and contexts work in the brain use a variety of techniques. They might inject animals with drugs, sometimes directly into specific parts of the brain. They might measure 
Figure 3

Practical applications of addiction research on animals. Research on classical conditioning and addiction can help scientists to learn about the behavioral and psychological aspects of addiction, as well as its molecular and genetic mechanisms. The behavioral results can help psychologists refine their counseling and therapy techniques, while the molecular and genetic results can help scientists develop new medicines. These new or improved therapies are then tested in humans and, if they work, used to help people with drug and alcohol addictions.

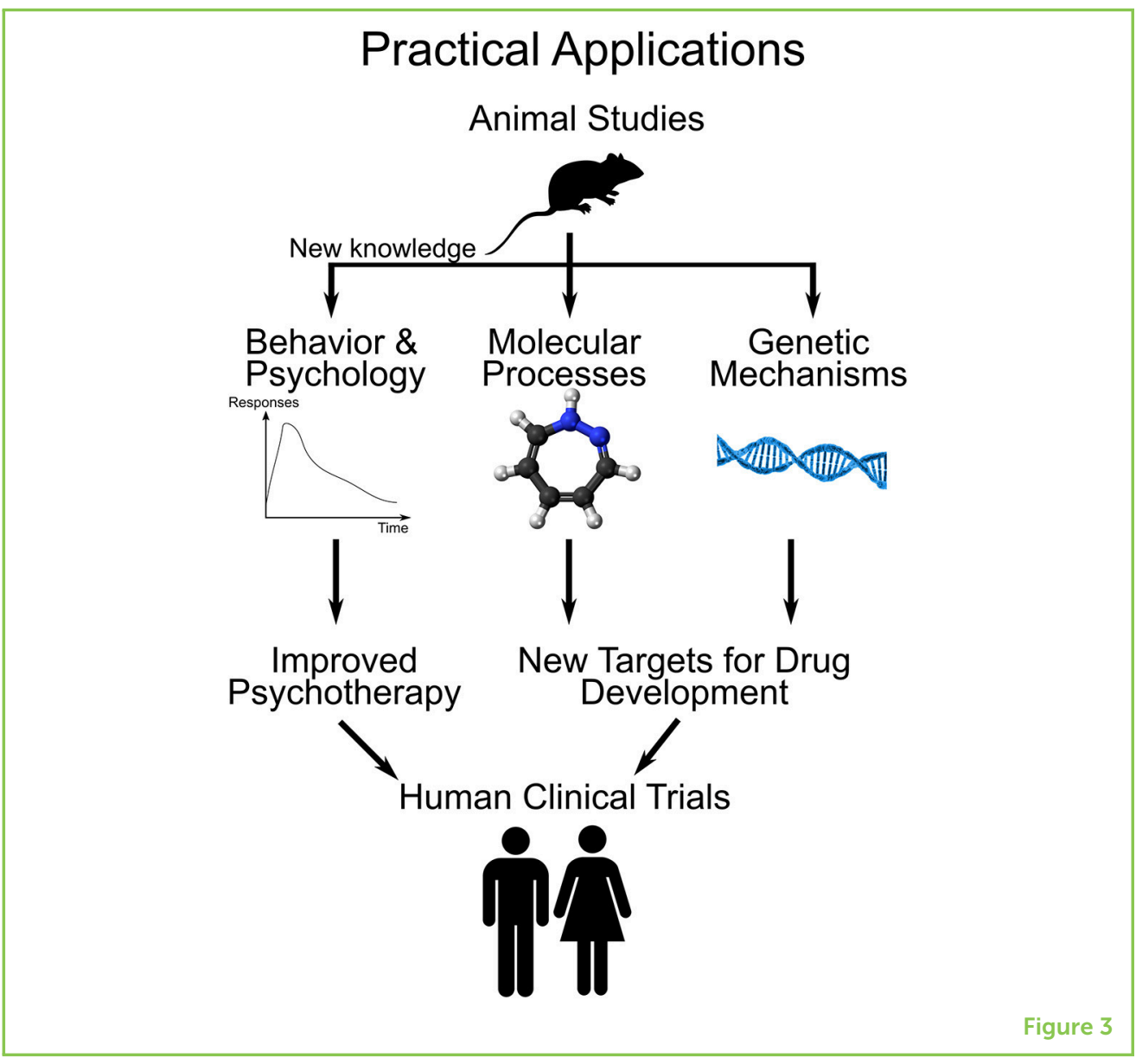

the way that neurons respond to cues, contexts, and drugs. Scientists can also study the way that genes interact with addiction and behavior. For example, a specific gene might turn on after an animal has been exposed to alcohol for a long time. So even though the classical conditioning procedures used in today's laboratories are often similar to what Pavlov did, scientists are learning new things about how conditioning works. For example, by injecting drugs into specific parts of the brain, scientists have learned more about which brain regions are involved in responding to a conditioned stimulus, which is a cue that has become associated with something motivating, such as food [3].

Learning more about classical conditioning and addiction in rats and mice helps scientists to find new treatments. Scientists take the most promising research results from animals and try to make new or better treatments for people (Figure 3). For example, one potential new treatment is to target the orexins, small messenger molecules made by a specific part of the brain called the hypothalamus. Scientists have been thinking about using drugs that block orexin messages mainly because of studies in animals showed they could help reduce alcohol consumption and relapse. For example, rats that were trained to press a lever to receive alcohol were given an orexin-blocking 
medication that prevented alcohol cues from causing the relapse effect during reinstatement [5]. Since orexin-blocking medications are safe for people to use, scientists suggest that they should be tested to see if they work for alcohol addiction [6].

\section{CONCLUSION}

Pavlov's dog showed that animals form links between cues and other highly motivating things, like food. Scientists have since learned that these mental links also occur in drug addiction, including alcohol addiction. In the laboratory, scientists use animals to study the way that these mental links or associations form between cues or contexts and drugs and alcohol. Scientists can use a variety of techniques to study the way the brain responds as these associations are forming, as treatment tries to break the associations, or to study what happens during relapse. As scientists learn more about how the brain works, they are coming up with new treatments that might one day help people struggling with addiction to drugs and alcohol.

\section{REFERENCES}

1. Pavlov, I. 1927. Conditional Reflexes: An Investigation of the Physiological Activity of the Cerebral Cortex. New York, NY: Dover Publications.

2. Jasinska, A. J., Stein, E. A., Kaiser, J., Naumer, M. J., and Yalachkov, Y. 2014. Factors modulating neural reactivity to drug cues in addiction: a survey of human neuroimaging studies. Neurosci. Biobehav. Rev. 38:1-16. doi: 10.1016/j.neubiorev.2013.10.013

3. Sciascia, J. M., Reese, R. M., Janak, P. H., and Chaudhri, N. 2015. Alcohol-seeking triggered by discrete pavlovian cues is invigorated by alcohol contexts and mediated by glutamate signaling in the basolateral amygdala.

Neuropsychopharmacology. 40:2801-12. doi: 10.1038/npp.2015.130

4. Bouton, M. E., and Swartzentruber, D. 1991. Sources of relapse after extinction in Pavlovian and instrumental learning. Clin. Psychol. Rev. 11:123-40. doi: 10.1016/0272-7358(91)90091-8

5. Lawrence, A. J., Cowen, M. S., Yang, H.-J., Chen, F., and Oldfield, B. 2006. The orexin system regulates alcohol-seeking in rats. Br. J. Pharmacol. 148:752-9. doi: 10.1038/sj.bjp.0706789

6. Campbell, E. J., Marchant, N. J., and Lawrence, A. J. 2018. A sleeping giant: suvorexant for the treatment of alcohol use disorder? Brain Res. doi: 10.1016/j.brainres.2018.08.005

SUBMITTED: 27 September 2018; ACCEPTED: 29 March 2019; PUBLISHED ONLINE: 11 April 2019.

EDITED BY: Jorge Galindo-Villegas, Nord University, Norway

CITATION: Khoo SY-S (2019) From Pavlov's Dog to Rats Using Drugs. Front. Young Minds 7:58. doi: 10.3389/frym.2019.00058 
CONFLICT OF INTEREST STATEMENT: The author declares that the research was conducted in the absence of any commercial or financial relationships that could be construed as a potential conflict of interest.

COPYRIGHT () 2019 Khoo. This is an open-access article distributed under the terms of the Creative Commons Attribution License (CC BY). The use, distribution or reproduction in other forums is permitted, provided the original author(s) and the copyright owner(s) are credited and that the original publication in this journal is cited, in accordance with accepted academic practice. No use, distribution or reproduction is permitted which does not comply with these terms.

\section{YOUNG REVIEWERS}

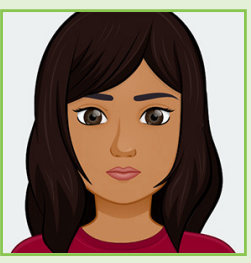

\section{CHAIMA, AGE: 16}

$\mathrm{Hi}$. I am a high school student who is very interested in the sciences, especially computer science. I love to read books and learn new languages.

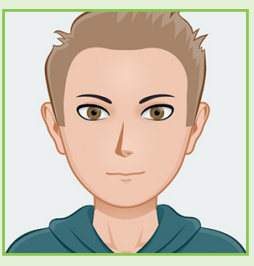

\section{FERGUS, AGE: 14}

I am 14 and study Biology and Physics. I play the drums and classical guitar. I also enjoy taking pictures of wildlife in the natural environment and playing sports, such as hockey and badminton.
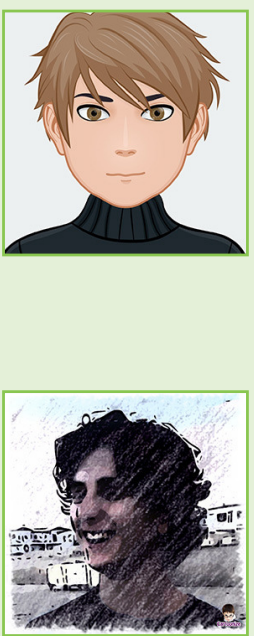

\section{JULIAN, AGE: 15}

I am a high school student interested in pursuing a career in STEM (Science, Technology, Engineering, and Mathematics). Hopefully 1 day I will be the academic sending in papers for Frontiers to review.

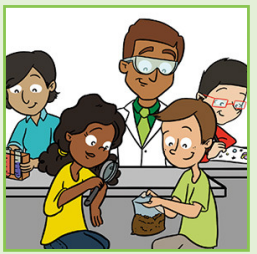

\section{SCHOOL WITHOUT WALLS, AGE: 13}

We are a group of students who are a part of the robotics club. We love to learn about new concepts emerging in math and science. 


\section{AUTHOR}

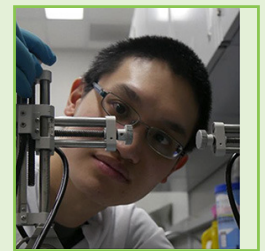

\section{SHAUN YON-SENG KHOO}

Shaun Khoo completed his Ph.D. in Psychology at the University of New South Wales in Sydney, Australia. During his Ph.D., he studied the role of the orexin system in addiction using rat models of alcohol, nicotine, and food-seeking. He is currently a postdoctoral fellow at the Université de Montréal where he is studying the neural circuitry underlying cocaine addiction. *shaun.khoo@umontreal.ca

†Present address: Department of Pharmacology and Physiology, Faculty of Medicine, Université de Montréal, Montreal, QC, Canada. 